\title{
25 Research Square \\ Developmental potency of goat embryos produced by intra cytoplasmic sperm injection and in vitro fertilization.
}

Joygeswar Bori ( $\sigma$ borijogya@gmail.com )

Nanaji Deshmukh Veterinary Science University

\section{Research Article}

Keywords: Goat, ICSI, IVF, micropipette, chemical activation

Posted Date: June 22nd, 2021

DOI: https://doi.org/10.21203/rs.3.rs-645083/v1

License: @ (1) This work is licensed under a Creative Commons Attribution 4.0 International License. Read Full License 


\section{Abstract}

The objective of this study was to standardize novel intracytoplasmic sperm injection (ICSI) technique, production of goat embryos by ICSI, in vitro fertilization (IVF) and comparison of their developmental potency. Immobilized sperm from epididymal semen with breaking tail were injected to mature metaphase ii oocytes by sharp micropipette of $5 \mu \mathrm{m}$ diameter, as well as in vitro fertilization was carried out. Icsi and IVF derived zygotes were cultured in rvcl-blast-bsa media after chemical activation with ionomycin, chx and 6-dmap. Sham injection was used as a control group. Results suggest that immobilized sperm with breaking tail microinjected by sharp injection pipette after chemical activation is an efficient approach for goat embryo production by ICSI. Satisfactory survival rate (83.2\%) was found by using sharp injection pipette of $5 \mu \mathrm{m}$ diameter. Chemical activation with ionomycin, chx and 6-dmap was found effective with activation rate of 63.33\%. Developmental rate of 2 cell, 4-8 cell, 8-16 cell, morula, blastocyst in ICSI and IVF group was $74.44 \%, 63.33 \%, 44.44 \%, 23.33 \%, 14.44 \%$ and $65.16 \%$, $57.42 \%, 49.03 \%, 38.71 \%, 23.23 \%$, respectively. Upon comparison, significantly higher $(\mathrm{p}<0.05)$ percentage of cleavage was found in ICSI group than IVF (73.40 $\pm 3.12 \%$ vs. $64.06 \pm 2.44 \%$, respectively). However, morula and blastocyst percentage was significantly higher $(p<0.05)$ in IVF group than ICSI $(23.20 \pm 2.73 \%$ vs. $37.90 \pm 3.15 \%$ and $14.56 \pm 1.75 \%$ vs. $21.05 \pm 2.09 \%$ ). It can be concluded that ICSI with sharp micropipette of $5 \mu$ diameter can be applied to assisted reproduction for in vitro goat embryo production.

\section{Introduction}

Reproductive biotechnologies applied to animal breeding have significant role in increasing the impact of superior genotypes in the population. The preliminary goal of in vitro production (ivp) of embryos is to rapidly gain genetic improvement of livestock (galli et al., 2003). The intracytoplasmic sperm injection (ICSI) technique has been the major breakthrough in the field of assisted reproduction. There are growing recent interest in the establishment of sperm mediated gene transfer (smgt) technology as a convenient and effective method for the simple production of transgenic animals (shadanloo et al., 2010). In animals especially in livestock, the ICSI technique could be an alternative approach to generate transgenic livestock using sperm as the dna carrier (perry et al., 1999b).

among the domestic ruminant species, most of the ICSI research has been performed in cattle followed by sheep. However, the technique has not been extensively studied in goat. Icsi is the mechanical insertion of a single sperm directly into the ooplasm of a mature oocyte using a microinjection pipette, bypassing barriers of fertilization including the process of sperm penetration through cumulus and corona cells, zona pellucida and oolemma by the process of directly depositing the sperm into the ooplasm (Wang et al., 2003). Therefore, ICSI offers an extremely interesting scope for studying some of the basic mechanisms underlying fertilization, e.g., oocyte activation, sperm decondensation, acrosomal reaction and pronucleus formation (rahman et al., 2007).

Slaughter house derived ovaries provide a cheap and abundant source of large number of oocytes for production of live goat kids. Thousands of oocytes are lost through atresia. This tremendous loss of genetic material could be reduced by harvesting oocytes from ovaries and using in vitro embryo production (ivep) techniques (hasler, 1998).

The objective of the present study was to develop a suitable protocol to produce ICSI-derived goat embryos from in vitro matured slaughter house ovaries in india by comparing with conventional IVF derived embryos.

\section{Meterials And Methods}


All plastic wares were purchased from falconware becton-dickinson (bedford, ma, usa) and

chemicals/biochemicals from sigma chemical co. (st. Louis, mo, usa), unless otherwise specified.

\section{Oocytes recovery and in vitro maturation}

Oocytes were aspirated from all the visible 2-6 mm sized follicles on the surface of goat ovaries collected from the small animal slaughterhouse and grade $\mathrm{i}$ and ii quality oocytes were matured in medium 199 (hyclone) with earle's salts, I-glutamine, sodium bicarbonate and $25 \mathrm{~mm}$ hepes containing $7.5 \%(\mathrm{v} / \mathrm{v}$ ) fetal bovine serum (fbs: hyclone, usa), supplemented with $10 \mu \mathrm{g} / \mathrm{ml}$ fsh, $10 \mu \mathrm{g} / \mathrm{ml}$ lh and $1 \mu \mathrm{g} / \mathrm{ml}$ estradiol. The cumulus oocyte complexes (cocs) were matured in groups of 20-25 in $50 \mu \mathrm{l}$ drops of maturation medium in a 35 mm culture petri dish. The droplets were then covered with sterile pre-equilibrated mineral oil and incubated at $38.5^{\circ} \mathrm{c}$ having $5 \%$ $\mathrm{co} 2$ and $95 \%$ relative humidity for $27 \mathrm{hrs}$ in $\mathrm{co} 2$ incubator. In the present study cumulus expansion was the criteria for evaluation of in vitro maturation of oocytes.

\section{Semen Treatment And Oocyte Preparation}

Semen was collected from goat epididymis obtained from slaughterhouse within 3-4 hours of slaughter. In laboratory, epididymis was washed 3 to 4 times in pre-warmed $\left(37^{\circ} \mathrm{C}\right)$ normal saline containing 400 iu/ml penicillin and $500 \mu \mathrm{g} / \mathrm{ml}$ streptomycin. After rinsing, extraneous tissue was removed with sterile scissor. Trimmed epididymis was rinsed twice in sterile dpbs followed by one rinsing in $70 \%$ ethanol followed by another rinsing with sterile dpbs. Epididymal sperm were harvested by multiple incisions on caudae epididymides and collected by washing with bo media in $15 \mathrm{ml}$ centrifuge tube. Sperm washing media were prepared by addition of $19 \mathrm{ml}$ bo-a stock solution to $9 \mathrm{ml}$ of bo-b stock solution along with $50 \mu \mathrm{l}$ of gentamicin and $0.3 \%$ bsa. Fresh epididymal semen $(1 \mathrm{ml}$ ) was added into $9 \mathrm{ml}$ of pre-equilibrated bo-a medium and centrifuged at $1000 \mathrm{rpm}$ for $10 \mathrm{~min}$. The supernatant was discarded and the sperm pellet was dissolved in $5 \mathrm{ml}$ fresh sperm washing medium and centrifuged again at $1000 \mathrm{rpm}$ for $10 \mathrm{~min}$. After swim-up motile sperm fraction was finally dissolved in $2 \mathrm{ml}$ of fertilization medium and kept in $5 \% \mathrm{CO}_{2}$ incubator at $38.5^{\circ} \mathrm{C}$ for 1 hour for capacitation. Fertilization media was prepared by addition of $8 \mathrm{ml}$ bo-a stock solution to $4 \mathrm{ml}$ of bo-b stock solution along with $50 \mu$ of gentamicin, $0.6 \% \mathrm{bsa}$ and $30 \mu \mathrm{g} / \mathrm{ml}$ heparin.

After in vitro maturation cumulus oocyte complexes of grade i and ii with expanded cumulus is partially decumulated by pipetting sequentially through glass pipettes for IVF, whereas those for ICSI were totally denuded by treating with hyaluronidase $(0.5 \mathrm{mg} / \mathrm{ml})$. Oocytes with first polar bodies were selected and cultured in in vitro maturation (ivm) medium in $5 \% \mathrm{CO}_{2}$, at $38.5-39{ }^{\circ} \mathrm{C}$ until IVF and ICSI procedure.

\section{In vitro fertilization}

In vitro matured oocytes were collected carefully from ivm drops and transferred in $35 \mathrm{~mm}$ dishes containing fertilization medium. The oocytes were then washed 2-3 times in the fertilization medium. For capacitation and fertilization, fertilization medium drops of $50 \mu \mathrm{l}$ were prepared in $35 \mathrm{~mm}$ dishes and covered with sterile mineral oil. After washing, the oocytes were transferred in fertilization medium drops (15-20 oocytes/drop). In vitro fertilization was done in medium having heparin and bsa, in addition to other chemicals. The matured oocytes were washed thrice in fertilization medium and transferred into the final fertilization drop (50 $\mu$ ), prepared in 35 $\mathrm{mm}$ petri dish, covered with sterile mineral oil (sigma). The final concentration of sperm used for IVF was adjusted @ of 1 to 2 million sperm/ml, depending upon the percentage of live sperm. The petri dish of fertilization drops was finally incubated at 5 percent $\mathrm{CO}_{2}$ at $38.5^{\circ} \mathrm{C}$ for 18 hours. 


\section{Intracytoplasmic Sperm Injection}

ICSI was performed on a small (35mm) falcon petri dish (becton dickinson labware, franklin lakes, nj, usa) under a nikon inverted microscope fitted with narishige hydraulic micromanipulators. The holding pipette had an inner diameter of $15 \mu \mathrm{m}$ and outer diameter $75 \mu \mathrm{m}$ (cook medical, k-hpip-1035). The injection pipette had an inner diameter of $5 \mu \mathrm{m}$ and outer diameter of $7 \mu \mathrm{m}$ (cook medical, k-mpip-1035). The injection and holding pipettes had a bevel angle of 35 degrees. The angle tip of the injection pipette should be almost parallel to the bottom of the dish, which is necessary to perform sperm immobilization. An aliquot $(1 \mu \mathrm{l})$ of washed sperm suspension was added to an elongated $5 \mu$-drop of injection medium (tcm-199, sigma, m-7528 $+10 \%$ fbs) with $10 \%$ polyvinilpirrolidone (pvp) solution. After ivm, one oocyte per drop was placed into a microdrop of $5 \mu$ l of injection medium covered with mineral oil. The head was aspirated first into the injection pipette. Then the sperm was brought to the pvp drop. An individual motile sperm was immobilized with the injection pipette by breaking its tail against the bottom of the dish by the tip of the injection needle. The tail was aspirated first into the injection pipette for injection. Each $\mathrm{m}$ ii oocytes was positioned with its first polar body at 6 or 12 o'clock position. The sperm was injected, head first, into the ooplasm of the oocyte through the zona pellucida. The injection pipette was in the 3 o'clock position. During the injection, cytoplasm was aspirated to approve that the oolema was broken. The spermatozoon was injected into the ooplasm with a minimum volume of medium ( $<5 \mathrm{pl})$ at the 9 o'clock position. As a control of activation of oocytes the sham injections (with vehicle medium only) were also performed in a similar manner. The oolema was ruptured and the ooplasm was aspirated into the injection pipette and re-injected into the oocyte with a minimum volume of medium.

\section{Activation Of Goat Oocytes}

Injected oocytes were activated as described by ongeri et al. (2001). Briefly, oocytes were exposed to $5 \mathrm{~mm}$ ionomycin in tcm-199 (sigma, m-7528) with 10\% fbs for 5 min. Then, each group was washed three times in tcm199 with 10\% fbs, and placed with $2 \mathrm{~mm}$ 6-dmap and $2 \mathrm{~mm}$ cyclohexamide in tcm-199 with 10\% fbs for 4 hours (ionomycin + chx +6-dmap). The oocytes were then washed in tcm-199 with $10 \%$ fbs and placed into $50 \mu \mathrm{l}$ drops of IVF medium.

\section{Culture Of Zygotes}

The oocytes after 18 hours of co-incubation with sperms of IVF and activated oocytes of ICSI showing male and female polar body (male polar body was identified by presence of sperm tail) group were transferred in $50 \mu \mathrm{l}$ drop of pre-equilibrated $\mathrm{rvcl}$ media ( $\operatorname{cook}{ }^{\circledR}$ ) with $1 \%$ fatty acid free bovine serum albumin (faf-bsa) in $35 \mathrm{~mm}$ petri dish covered with mineral oil. This petri dish was transferred in humidified chamber of $5 \% \mathrm{co} 2$ at $38.5^{\circ} \mathrm{C}$ and kept for 3 days (72 hours). The embryos were observed for their development at different time intervals. Only those embryos which showed cleavage and development were selected and put in the petri dish having the $50 \mu$ drop of blastocyst media (cook $\left.{ }^{\circledR}\right)$ with $1 \%$ bsa for further 5-7 days. Different stages of embryos were recorded during this period.

\section{Statistical analysis}

the data obtained from the present study was analyzed by the standard method elaborated by snedecor and cochran (1994) for means \pm standard error and ' $t$ ' test. Differences with a $p<0.05$ were considered statistically significant.

\section{Results}

A good numbers of oocytes can be matured from slaughter house goat ovaries. Total 744 oocytes were aspirated from 269 ovaries, indicating an average of 2.76 oocytes recovered per ovary. Out of these 744 oocytes, 287 
(38.58\%) oocytes were of grade i, 247 (33.20\%) of grade ii and 206 of grade iii (27.69\%). Oocytes of grade i and ii, i.e. 534 were set for maturation, of which 376 oocytes $(70.41 \%)$ showed the first polar body formation.

Efficiency rate of ICSI was found satisfactory by using sharp microinjection pipette of $5 \mu \mathrm{m}$ diameter (Fig. 3). Lower percentage (16.79\%), of oocytes damaged by injection, higher percentage $(83.21 \%)$ of oocytes surviving the injection, and lower percentage (17.78\%) of oocytes degenerated during 13-21 hours of in vitro culture signifies less damage caused by sharp microinjection pipette of small diameter. Goat oocytes needed a chemical activation after ICSI for activation and cleavage. Chemical activation was done with ionomycin, cyclohexamide and 6-dmap. Higher percentage (74.44\%) of oocytes activated and cleaved shows the efficiency of ionomycin, cyclohexamide and 6-dmap for chemical activation after ICSI.

The developmental potency of goat embryos produced by ICSI, IVF and sham injection is shown in table 1 . For ICSI group, out of 90 oocytes 67 (74.44\%) were cleaved (2 cell). After culturing the cleaved oocytes, different developmental stages observed were $4-8$ cell 57 (63.33\%), 8-16 cell 40 (44.44\%), morula 21 (23.33\%) and blastocyst 13 (14.44\%). For IVF group, out of 155 oocytes 101 (65.16\%) cleaved (2 cell). After culturing the cleaved oocytes, different developmental stages observed were, $4-8$ cell 89 (57.42\%), 8-16 cell 76 (49.03\%), morula 60 (38.71\%) and blastocyst 36 (23.23\%). As expected for sham injected control group, out of 22 oocytes no cleavage or further embryonic development was observed which is shown in Fig. 4.

Different developmental stages viz. 2 cells, 4-8 cell, 8-16 cell, morula and blastocyst were compared for ICSI and IVF group in ravel-blast-base media. The number of morula and blastocysts was significantly higher $(p<0.05)$ in IVF group as compared to ICSI group (37.90 $\pm 3.15 \%$ vs. $23.20 \pm 2.73 \%$ and $21.05 \pm 2.09 \%$ vs. $14.56 \pm 1.75 \%$ ) However, number of cleavage ( 2 cell stage) was found significantly higher $(p<0.05)$ in ICSI group than IVF group (73.40 \pm 3.12 vs. $64.06 \pm 2.44)$. Detail of micromanipulation and acolyte activation is shown in Table 2.

\section{Discussion}

A suitable ICSI protocol for the production of goat embryos from in vitro derived oocytes obtained from slaughterhouse ovaries and epididymal sperm was demonstrated in our study. Sharp injection pipette of $5 \mu \mathrm{m}$ diameter was found efficient for injection with satisfactory survival rate (83.21\%) and lower degeneration rate (17.78\%) during in vitro culture. Chemical activation with ionomycin, cyclohexamide and 6-dmap was found satisfactory for oocyte activation and cleavage (63.33\%).

One of the important things to initiate the sperm nucleus decondensation and oocyte activation is the mutual interaction of the ooplasmic factors and sperm sub-membrane components (perry et al., 1999a). Permeabilization of the sperm membrane is a prerequisite of this process during normal fertilization (Kasai et al., 1999) or IVF. It is known that a permeabilization treatment of the sperm membrane prior to ICSI helps the process of decondensation of head sperm. In this study, sperm permeabilization was done by tail breaking by injection pipette as describe by Rahman et al. (2007). It was found that it speed up the procedure and more easier than tail cutting. Palermo et al. (1996) found that the fertilization rate of human oocytes following ICSI using testicular spermatozoa increased significantly when sperm tails were scored more harshly by injection pipette. In our experiment the same technique of harsh hitting of spermatozoa tail was applied which resulted in successful embryo production. In this study, immobilized goat sperm cells were used for intracytoplasmic sperm injection to produce good quality embryos. Results indicated that goat sperm motility was not required under the ICSI procedure. This result agrees with results from the human (Palermo et al., 1992) and the cow (Goto et al., 1990). It 
was also found that the motile spermatozoa after injection keep moving resulted in degeneration of oocytes and did not reached even cleavage stage. The results agree with Kimura and Yanagimachi (1995). Continuous movement of sperm cells within the cytoplasm may disorganize the oocytes structural elements and/or disturb the "oolemma's wound healing" (Kimura and Yanagimachi, 1995). In the present study it was also observed that $17.78 \%$ oocytes degenerate during in vitro culture after sperm injection which may be due to disorganization of oocytes' structural elements and failure to heal the "oolemmal wound" caused by injection.

Since the oolemma of goat metaphase ii oocytes is characterized by extreme elasticity (wang et al., 2003), like that of bovine oocytes (Gagne et al., 1995), it's very difficult to broken the oolemma with micropipette insertion. In fact, spermatozoa could have been expelled from the ooplasmic furrow created by the injection pipette. It's very difficult to inject a sperm into the ooplasm without damaging the oocyte membrane and cytoplasmic structure (Rahman et al., 2007). In our present study $17.78 \%$ oocytes damaged due to injection. This may be due to factors mentioned above. To overcome the difficulty of sperm penetration through the oolemma and improve the efficiency of ICSI many workers reported successful application of piezo-drill, a device that generates mechanical pulses through a piezo-actuator to break the oolemma during icsi with a survival rate of $97 \%$ (wang et al., 2003). However, sophisticated equipment and extensive manipulating experience are needed to use piezo-driven micromanipulator. Rahman et al. (2007) noticed in his study that the main cause of oocyte degeneration was the failure of the injected oocytes to heal the damage caused by the mechanical insertion of the needle, especially when using a needle of larger diameter without a spike. This problem was minimized by using a needle of $5 \mu \mathrm{m}$ inner diameter and outer diameter of $7 \mu \mathrm{m}$ (cook medical, Bloomington, USA). Breaking the oolemma of goat metaphase ii oocyte was confirmed by aspiration of cytoplasm after injection followed by reinjection of the cytoplasmic material. In our present study $83.21 \%$ oocyte survived after injection which is lower than piezo-driving actuator (97\%) as reported by Wang et al. (2003).

In mice, Kimura and Yangimachi (1995) demonstrated that mouse oocytes injected with testicular and epididymal spermatids or spermatocytes were unable to activate oocytes. Furthermore, oocytes containing injected spermatids or spermatocytes had to be activated artificially to support normal fertilization and full term development. These results demonstrate that artificial stimulation can support full development of mouse oocytes injected with spermatids or spermatocytes. In our study, epididymal sperm where injected for fertilization. Immature spermatids and spermatocytes need chemical activation for further embryonic development. We observed that oocyte activation was more affected by chemical activation than by mechanical sperm injection. Mechanical sperm injection into the ooplasm is enough to activate the oocyte in human (Palermo et al., 1992), hamster (Hoshi et al., 1992) and mouse (Kimura \& Yanagimachi, 1995). But, it has been demonstrated that some species, such as cattle (Keefer et al., 1990) and pigs (Proust and Roth, 2003) need the aid of chemical activation after ICSI to improve the embryo development. A number of reports have suggested that acolyte activation could be improved following ICSI with different stimuli like calcium ionosphere in goats (Keskintepe et al., 1997), 6dimethylaminopurine in cattle (Rho et al., 1998), and electrical pulses in humans (Yanagida et al., 1999) and pigs (Lai et al., 2001). Protocols with the best results in goat were those that combined ionomycin with 6-dmap (Ongeri et al., 2001). In our study, we used conventional manual needle injection, slaughter house derived goat oocytes and epididymal spermatozoa with broken tails, and under these conditions chemical stimulation was needed to achieve the oocyte activation. Ionomycin, $\mathrm{CHX}$ and 6-dmap was used to activate injected oocytes. A good percentage (63.33\%) of zygotes with male and female polar body was obtained with ICSI plus chemical stimulation. However, $21.11 \%$ oocytes were not activated. Jiménez-macedo et al. (2005) reported that $38.6 \%$ of ICSI embryos with chemical activation by ionomycin and 6-dmap showed normal fertilization and $42.8 \%$ were not 
activated. In our study activated oocytes were found to be higher (63.33\% vs. 38.6\%) than reported by Jiménezmacedo et al. (2005) and not activated oocytes were lower (21.11\% vs. $42.8 \%)$. Artificial oocyte activation always carries the risk of an induction of parthenogenesis. That is why it's necessary to include sham (injected oocyte with vehicle but without sperm) oocytes as control group of mechanical activation. As expected, out of 22 oocytes no oocytes showed signs of embryonic development.

In order to increase the IVEP efficiency in goat the identification and selection of a suitable system capable of supporting embryonic development in vitro is critical. Using a complex and sequential media consisting of MTALP medium with OGS (20\%) for first 24 hours, MKOSM with fatty acid free BSA (1\%) from 96-192 hours, Wang et al. (2003) obtained a higher cleavage rate (89\%), morula (41\%) and blastocyst (21.1\%) production. However, using a slightly modified SOF medium, Jimenez- macedo et al. (2005), Jiménez- macedo et al. (2006) and Keskintepe et al. (1997) obtained $53.40 \%, 66.90 \%$ and $62.20 \%$ cleavage and $2.7 \%, 10.60 \%$ and $25 \%$ blastocyst, respectively. Shadanloo et al. (2010) found $84.80 \%$ cleavage and $29.50 \%$ blastocyst using immobilized frozen semen after activation with ionomycin. RVCL is a commercial medium from cook's (Australia), which is basically used for cleavage. However, it has been successfully used for development up to blastocyst stage in buffalo. Shah et al. (2008) used RVCL of cloned embryos and reported significantly higher blast cyst development as compared to mcr2 and msof media. In our study RVCL-blast-BSA media was used as a sequential media. Out of 90 oocytes 67 (74.44\%) were cleaved (2 cell), 57 (63.33\%) were 4-8 cell, 40 (44.44\%) were 8-16 cell, 21 (23.33\%) were morula and 13 (14.44\%) were blastocyst. Lower percentage of cleavage rate, morula and blastocyst production was obtained than Wang et al. (2003). However, result of the present study is still satisfactory because like Wang et al., (2003) a piezo micromanipulator was not used to facilitate sperm injection. Result of the present study is comparable with Jiménez- macedo et al. (2005) and more than Rahman et al. (2007). Rahman et al. (2007) reported zygote $54.1 \pm 5.5 \%$, cleaved and $2-8$ cell $18.2 \pm 6.9 \%$ and $9-16$ cell and morula $2.9 \pm 2.9 \%$.

Comparison of developmental potency in ICSI and IVF embryo indicated efficiency for in vitro embryo production in goat over ICSI method. Jiménez- macedo et al. (2005) compared developmental potency of goat embryos produced by ICSI and IVF with different culture media and activation protocol. They reported that the percentage of embryo reaching $8-16$ cell stage was significantly higher $(p<0.005)$ in the ICSI than in the IVF group $(22.8 \%$ and $10.3 \%$, respectively) and the percentage of zygotes was significantly higher $(p<0.05)$ in ICSI than in IVF group ( $40 \%$ vs. $25.1 \%)$. In the present study the percentage of 2 cell stage embryos were significantly higher $(p<0.05)$ in ICSI group than IVF $(73.40 \pm 3.12 \%$ vs. $64.06 \pm 2.44 \%)$ in RVCL-blast-BSA media. However, percentage of morula and blastocyst production significantly higher $(p<0.05)$ in IVF group than ICSI $(37.90 \pm 3.15 \%$ vs. $23.20 \pm 2.73 \%$ and $21.05 \pm 2.09 \%$ vs. $14.56 \pm 1.75 \%)$. The higher percentage of cleavage observed in ICSI oocytes compared to IVF oocytes could be due to: (1) the activation protocol used after ICSI procedure and (2) ICSI allowing the fertilization of all competent oocytes. No significant difference was found in 4-8 cell and 8-16 cell stage embryos.

\section{Declarations}

\section{Conflict of interest}

I, Dr. Joygeswar bori, confirm that the manuscript has been written, read and approved by myself and that there are no other persons who fit the criteria for authorship but are not listed. 


\section{Acknowledgement}

The authors are thankful for the financial support provided by national agricultural innovation project, Indian council of agricultural research, government of India, New Delhi and department of biotechnology, government of India, New Delhi for providing junior research fellowship to the first author.

\section{Conclusion}

It can be concluded that immobilized sperm with breaking tail microinjected by sharp injection pipette after chemical activation is an efficient approach for goat embryo production by ICSI.. Chemical activation with Ionomycin, $\mathrm{CHX}$ and 6 -dmap was found to be effective. ICSI with sharp micropipette of $5 \mu \mathrm{m}$ diameter can be applied to assisted reproduction for in vitro goat embryo production.

\section{References}

1. Galli C, Duchi R, Crotti G, Turini P, Ponderato N, Colleoni S, Lagutina I, Lazzari G (2003).Bovine Embryotechnologies. Theriogenology, 59: 599-616

2. Shadanloo F, Najafi MH, Hosseini SM, Hajian M, Forouzanfar M, Ghaedi K, Abedi P, Ostadhosseini S, Hosseini L, Eskandari-Nasab MP, Esfahani MH (2010) Sperm status and DNA dose play key roles in sperm/icsimediated gene transfer in caprine. Mol Reprod Dev 77:868-875

3. Perry AC, Wakayama T, Kishikawa H, Kasai T, Okabe M (1999) Mammalian transgenesis by intracytoplasmic sperm injection.Science, 284: 1180-1184

4. Wang B, Baldassarre H, Pierson J, Cote F, Rao KM (2003) The In Vitro and In Vivo Development Of Goat Embryos Produced By Intracytoplasmic Sperm Injection Using Tail Cut Spermatozoa. Zygote 11:219-227

5. Rahman ANMA, Abdullah RB, Khadijah W, W.E (2007) Goat embryos development from in vitro matured oocytes of heterogenous quality through intracytoplasmic sperm injection technique. Biotechnology 6:373382

6. Hasler JF (1998) The Current Status Of Oocyte Recovery, In Vitro Embryo Production, and Embryo Transfer In Domestic animals, With An Emphasis On The Bovine. Journal Of Animal Science 76:52-74

7. Palermo GD, Schlegel PN, Colombero LT, Zaninovic N, Moy F, Rosenwaks Z (1996) Aggressive sperm immobilization prior to ICSI with immature spermatozoa improves fertilization and pregnancy rates. Hum Reprod 11:1023-1029

8. Palermo GD, Joris H, Devroey P, Van Steirteghem AC (1992).pregnancies after intracytoplasmic injection of a single spermatozoon into an oocyte. Lancet, 340: 17-18

9. Goto K, Kinoshita A, Takuma Y, And Ogawa K (1990) Fertilization of bovine oocytes by the injection of immobilized, killed spermatozoa. Vet Rec 139:494-495

10. Kimura y, Yanagimachi r (1995) Intracytoplasmic sperm injection in the mouse. Biology Of Reproduction 52:709-720

11. Gagne M, Pothier F, sirard MA (1995) Effect of microinjection time during post fertilization s-phase on bovine embryonic development. Mol Reprod Dev 41:184-194

12. Hoshi K, Yanagida K, Sato A (1992) Pretreatment Of Hamster Oocytes With $\mathrm{Ca}^{2+}$ Ionophore To Facilitate Fertilization By Ooplasmic Microinjection. Hum Reprod 7:871-875 
13. Keefer CL (2004) Production Of Bioproducts Through The Use Of Transgenic Animal Models. Animal Reproduction Science 82-83:5-12

14. Probst S, Rath D (2003) Production of piglets using intracytoplasmic sperm injection (ICSI) with flowcytometrical sorted boar semen and artificially activated oocytes. Theriogenology 59:961-973

15. Keskintepe L, Morton P, Smith SE, Tucker MJ, Simplicio AA, Brackett BG (1997) Caprine Blastocyst Formation Following Intracytoplasmic Sperm Injection And Defined Culture. Zygote 5:261-265

16. Yanagida K, Katayose H, Yazawa H, Kimura Y, Sato A, Yanagimachi H, Yanagimachi R (1999) Successful Fertilization And Pregnancy Following ICSI And Electrical Oocyte Activation. Hum Reprod 14:1307-1311

17. Rho GJ, Kawarsky S, Johnson WH, Kochhar K, Betteridge KJ (1998) Sperm and oocyte treatments to improve the formation of male and female pronuclei and subsequent development following intracytoplasmic sperm injection into bovine oocytes. Biology Of Reproduction 59:918-924

18. Lai L, Sun Q, Wu G, Murphy CN, Kuhholzer B, Park KW, Bonk AJ, Day BN, Prather RS (2001) Development of porcine embryos and offspring after intracytoplasmic sperm injection with liposome transfected or nontransfected sperm into in vitro matured oocytes. Zygote 9:339-346

19. Ongeri EM, Bormann CL, Butler, Behboodi RE, E (2001) Development of goat embryos after in vitro fertilization and parthenogenetic activation by different methods. Theriogenology 55:1933-1945

20. Jiménez-Macedo AR, Anguita B, Izquierdo D, Mogas T, Paramio MT (2006) Embryo development of prepubertal goat oocytes fertilized by intracytoplasmic sperm injection (icsi) according to oocyte diameter. Theriogenology 66:1065-1072

21. Jiménez-Macedo AR, Anguita B, Paramio MT (2005) Comparision Between Intracytoplasmic Sperm Injection And In Vitro Fertilization Employing Oocytes Derived From Prepubertal Goats. Theriogenology 64:1249-1262

22. Shah RA, George A, Singh MK, Kumar D, Chauhan MS, Manik R, Palta P, Singla SK (2008) Handmade Cloned Buffalo Embryos: Comparison Of Different Media And Culture Systems. Cloning Stem Cells 10:435-441

\section{Tables}

Table 1. Developmental potency of intracytoplasmic sperm injection, in vitro fertilization and sham injection group of goat embryos

$\mathrm{N}(\%)$ of activated zygotes (fertilized), not activated and degenerated are calculated from number of intact oocytes taken for chemical activation. 


\begin{tabular}{|c|c|c|c|c|c|c|}
\hline Groups & $\begin{array}{l}\mathrm{N} \text { of oocyte } \\
\text { Taken for } \\
\text { evaluation }\end{array}$ & $\begin{array}{l}2 \text { cells } \\
(\%)\end{array}$ & $\begin{array}{l}4-8 \text { cells } \\
\text { (\%) }\end{array}$ & $\begin{array}{l}8-16 \text { cells } \\
(\%)\end{array}$ & $\begin{array}{l}\text { Morula } \\
(\%)\end{array}$ & $\begin{array}{l}\text { Blastocyst } \\
\text { (\%) }\end{array}$ \\
\hline In vitro fertilization & 90 & $\begin{array}{l}64.06 \pm \\
2.44^{\mathrm{a}}\end{array}$ & $\begin{array}{l}56.81 \pm \\
3.05^{\mathrm{a}}\end{array}$ & $\begin{array}{l}48.45 \pm \\
2.58^{\mathrm{a}}\end{array}$ & $\begin{array}{l}37.90 \pm \\
3.15^{\mathrm{b}}\end{array}$ & $\begin{array}{l}21.05 \pm \\
2.09^{b}\end{array}$ \\
\hline $\begin{array}{l}\text { Intra } \\
\text { Cytoplasmic sperm } \\
\text { injection }\end{array}$ & 155 & $\begin{array}{l}73.40 \pm \\
3.12^{\mathrm{b}}\end{array}$ & $\begin{array}{l}65.46 \pm \\
5.12^{\mathrm{a}}\end{array}$ & $\begin{array}{l}44.09 \pm \\
3.92^{\mathrm{a}}\end{array}$ & $\begin{array}{l}23.20 \pm \\
2.73^{a}\end{array}$ & $\begin{array}{l}14.56 \pm \\
1.75^{a}\end{array}$ \\
\hline Sham injection & 22 & 0 & 0 & 0 & 0 & 0 \\
\hline
\end{tabular}


Table 2

Micromanipulation and chemical activation (ionomycin + cyclohexamide + 6- dimethylaminopyridine) efficiency of intracytoplasmic sperm injection

\begin{tabular}{|c|c|c|c|c|c|c|c|c|}
\hline $\begin{array}{l}\text { Trial } \\
n\end{array}$ & $\begin{array}{l}\text { Nof } \\
\text { oocytes } \\
\text { injected }\end{array}$ & $\begin{array}{l}\text { Nof (\%) } \\
\text { oocytes } \\
\text { damaged } \\
\text { By } \\
\text { injection }\end{array}$ & $\begin{array}{l}\text { Nof (\%) } \\
\text { oocytes } \\
\text { surviving } \\
\text { The } \\
\text { injection }\end{array}$ & $\begin{array}{l}\text { Nof (\%) } \\
\text { oocytes } \\
\text { discarded }\end{array}$ & $\begin{array}{l}\text { Nof (\%) } \\
\text { intact } \\
\text { oocytes } \\
\text { taken for } \\
\text { chemical } \\
\text { activation }\end{array}$ & $\begin{array}{l}\text { Nof (\%) } \\
\text { Oocytes } \\
\text { Degenerated } \\
\text { During 13- } \\
21 \text { hours } \\
\text { Culture }\end{array}$ & $\begin{array}{l}\text { Nof (\%) } \\
\text { activated } \\
\text { zygote } \\
\text { (fertilized) }\end{array}$ & $\begin{array}{l}\text { Nof (\%) } \\
\text { oocytes } \\
\text { not } \\
\text { activated }\end{array}$ \\
\hline 1 & 13 & 3 (23.08) & $\begin{array}{l}10 \\
(76.92)\end{array}$ & 1 (7.69) & 9 (69.23) & $1(11.11)$ & $6(66.67)$ & $2(22.22)$ \\
\hline 2 & 15 & $4(26.67)$ & $\begin{array}{l}11 \\
(73.33)\end{array}$ & 1 (6.67) & 8 (53.33) & $1(12.50)$ & $6(75.00)$ & $3(37.50)$ \\
\hline 3 & 16 & $5(31.25)$ & $\begin{array}{l}11 \\
(68.75)\end{array}$ & $2(12.50)$ & $\begin{array}{l}10 \\
(62.50)\end{array}$ & $1(10.00)$ & $7(70.00)$ & $1(10.00)$ \\
\hline 4 & 11 & $2(18.18)$ & $9(81.82)$ & 1 (9.09) & 8 (72.72) & $2(25.00)$ & $4(50.00)$ & $2(25.00)$ \\
\hline 5 & 13 & $2(15.38)$ & $\begin{array}{l}11 \\
(84.62)\end{array}$ & $2(15.38)$ & $9(69.23)$ & $2(22.22)$ & $4(44.44)$ & 3 (33.33) \\
\hline 6 & 11 & 1 (9.09) & $\begin{array}{l}10 \\
(90.91)\end{array}$ & $2(18.18)$ & 9 (81.82) & $1(11.11)$ & $6(66.67)$ & $1(11.11)$ \\
\hline 7 & 9 & $1(11.11)$ & 8 (88.89) & $1(11.11)$ & $5(55.56)$ & $3(60.00)$ & $3(60.00)$ & $1(20.00)$ \\
\hline 8 & 10 & $2(20.00)$ & $8(80.00)$ & $3(30.00)$ & $7(70.00)$ & $1(14.28)$ & $2(28.57)$ & $2(28.57)$ \\
\hline 9 & 17 & $1(5.88)$ & $\begin{array}{l}16 \\
(94.11)\end{array}$ & 3 (17.65) & $\begin{array}{l}14 \\
(82.35)\end{array}$ & 2 (14.29) & 9 (64.29) & $2(14.29)$ \\
\hline 10 & 16 & $1(6.25)$ & $\begin{array}{l}15 \\
(93.75)\end{array}$ & $1(6.25)$ & $\begin{array}{l}11 \\
(68.75)\end{array}$ & 2 (18.18) & $\begin{array}{l}10 \\
(90.91)\end{array}$ & 2 (18.18) \\
\hline Total & 131 & $\begin{array}{l}22 \\
(16.79)\end{array}$ & $\begin{array}{l}109 \\
(83.21)\end{array}$ & $\begin{array}{l}17 \\
(12.98)\end{array}$ & $\begin{array}{l}90 \\
(68.70)\end{array}$ & 16 (17.78) & $\begin{array}{l}57 \\
(63.33)\end{array}$ & $\begin{array}{l}19 \\
(21.11)\end{array}$ \\
\hline
\end{tabular}

\section{Figures}

Figures 3 and 4 are available in the Supplementary Files.

\section{Supplementary Files}

This is a list of supplementary files associated with this preprint. Click to download.

- floatimage1.png

- floatimage2.jpeg 